\title{
Inflammatory Bowel Disease and the Risk of Fracture
}

\author{
TJEERD-PIETER VAN STAA, *,‡,§ CYRUS COOPER, ${ }^{\ddagger}$ LISTY SAMUELS BRUSSE, $*$ \\ HUBERT LEUFKENS,* MUHAMMAD K. JAVAID, ${ }^{\dagger}$ and NIGEL K. ARDEN ${ }^{\dagger}$ \\ $*$ Department of Pharmacoepidemiology and Pharmacotherapy, University of Utrecht, Utrecht, The Netherlands; ${ }^{*}$ Medical Research Council \\ Environmental Epidemiology Unit, Southampton General Hospital, University of Southampton, Southampton, England; and \$Procter \& Gamble \\ Pharmaceuticals, Staines, England
}

Background \& Aims: Although patients with inflammatory bowel disease (IBD) have reduced bone mass, there is controversy whether there is an increased risk of fracture. This study examines the risk of fracture and its predictors in patients with IBD. Methods: In a primary care-based nested case-control study, 231,778 fracture cases and 231,778 age- and sex-matched controls were recruited. A history of IBD was assessed from medical records. Results: The prevalence of IBD was 156 and 282 per 100,000 for Crohn's disease (CD) and ulcerative colitis (UC), respectively. Patients with IBD had an increased risk of vertebral fracture (odds ratio [OR], 1.72; 95\% confidence interval $[\mathrm{Cl}], 1.13-2.61)$ and hip fracture (OR, 1.59; 95\% Cl, 1.14-2.23). The risk of hip fracture was greater in patients with CD (OR, 1.86; 95\% $\mathrm{Cl}, 1.08-3.21)$ compared with UC (OR, 1.40; $95 \% \mathrm{Cl}$, $0.92-2.13)$. Disease severity, assessed by the number of symptoms, predicted fracture even after adjusting for corticosteroid use (OR, 1.46; 95\% Cl, 1.04-2.04). Only $13 \%$ of patients with IBD who had already sustained a fracture were on any form of antifracture treatment. Conclusions: Patients with IBD have a higher risk of fracture due to both disease activity and use of oral corticosteroids. However, few of these patients are receiving optimal bone-sparing therapy, highlighting the importance of increasing awareness of osteoporosis in those managing these patients.

$\mathrm{O}$ steoporotic fractures constitute a major health problem and cause considerable morbidity and mortality among the elderly. The most common sites of osteoporotic fracture are the spine, proximal femur, and distal forearm. Several epidemiologic studies have reported an increased prevalence of low bone mass in patients with IBD, ${ }^{1-24}$ and the pathogenesis is likely to be multifactorial, including use of oral corticosteroids, vitamin $\mathrm{D}$ deficiency, malabsorption, malnutrition, hypogonadism, and systemic inflammation. ${ }^{25-27}$

There is limited information on the risk of fracture in patients with inflammatory bowel disease (IBD). A number of uncontrolled studies have reported that between $5 \%$ and $27 \%$ of patients with IBD have sustained a fracture. ${ }^{1,5,8,10,13,17,24}$ More recently, a cohort study of patients with IBD found a $41 \%$ increase in the risk of fracture compared with controls, with similar increases for Crohn's disease (CD) and ulcerative colitis (UC) ${ }^{4}$ These results differ from a large Danish case-control study that found a 2.5 -fold increase in the risk of fracture among women with $\mathrm{CD}$ but not men with $\mathrm{CD}$ or patients with UC. ${ }^{22}$ A study of a hospital discharge registry found a small overall increased risk in patients with $C D$ but not those with UC. ${ }^{23}$ The aim of the present study was to evaluate the risk of fracture in patients with IBD and, more specifically, the relative contributions of oral corticosteroid treatment versus disease severity to risk of fracture in a population-based study.

\section{Patients and Methods}

The data used in this nonconcurrent case-control study were obtained from the General Practice Research Database (GPRD), which is managed by the Medicines Control Agency in the United Kingdom. ${ }^{28}$ This database comprises the entire computerized medical records of a sample of general practitioners in the United Kingdom. General practitioners play a key role in the U.K. health care system because they are responsible for primary health care and specialist referrals. All members of the population are registered with a single practice, which centralizes medical information not only from the general practitioners themselves but also from specialist referrals and hospital attendances. The present study included 683 practices currently incorporated in the GPRD and thereby comprised a $6 \%$ sample of the U.K. population. The data recorded in the GPRD include demographic information, prescription details, clinical events, preventive care provided, specialist referrals, hospital admissions, and major outcomes. Clinical data are stored and retrieved by means of Oxford Medical Information Systems and Read codes for diseases that are cross-referenced to the International Classification of Diseases (ICD-9). The data

Abbreviations used in this paper: BMD, bone mineral density; $\mathrm{Cl}$, confidence interval; GPRD, General Practice Research Database; OR, odds ratio.

(C) $\mathbf{2 0 0 3}$ by the American Gastroenterological Association 0016-5085/03/\$30.00 doi:10.1053/j.gastro.2003.09.027 
quality of each entry into the GPRD is measured against specific targets, developed by comparisons with external statistics, to ensure research standards are met. Only data from practices that pass this quality control are compiled to form the GPRD database. Data collection for the GPRD began in 1987 and, for this study, ended in July 1999.

\section{Study Population}

A case-control study was conducted using information from the GPRD. Case patients were permanently registered patients aged 18 years and older who had a fracture at any site in their medical records. Control patients were adults without a history of fracture in their medical records. They were matched to case patients by age (within 1 year) and sex; if no control patient was found, then the age criterion was expanded. The index date of the case patients was the date of the first fracture after GPRD collection started. Further details on the study population are provided elsewhere. ${ }^{29}$

The number of patients with a history of IBD (either CD or UC) was examined in both case patients and control patients. Severity of IBD was assessed using 2 factors: a history of general practitioner visits for symptoms of IBD (diarrhea, abdominal pain, anemia, rectal bleeding, or weight loss) and hospitalization for a gastrointestinal disorder in the 12 months before the index date. In addition, the use of medication for the treatment of IBD was examined. Current users of oral corticosteroids were defined as patients who had received at least one prescription in the 3 months before the index date. Rectal corticosteroid use was examined separately. Prescriptions for aminosalicylates and other disease-modifying agents (methotrexate, azathioprine, and cyclosporine) were also recorded. Furthermore, use of bone-protective agents, including bisphosphonates, hormone replacement therapy, and vitamin D, was examined.

As part of this study, the general practitioners of 25 randomly selected patients with CD and 25 patients with UC were sent questionnaires to validate the diagnosis of IBD. IBD was confirmed in $92 \%$ of cases of CD and UC. Of the 4 cases not confirmed, one had suspected CD that was diagnosed as irritable bowel syndrome after further investigation and another had barium enema results showing that very early UC could not be excluded. Of the 23 confirmed cases of UC, 11 had left-sided and 8 had diffuse UC (no data for 4 cases). The location for CD was the small bowel in 11 and colitis in 12 . Another validation study, conducted independently of this study, also reported a high level of accuracy of IBD recording. ${ }^{30}$ Furthermore, the estimated prevalence of CD and UC in the GPRD population was found to be comparable to that reported in another U.K. study. ${ }^{31}$

Age- and sex-specific incidence rates of fracture were calculated in the total GPRD population. ${ }^{32}$ The 10-year risk of fracture was derived for women and men with IBD by multiplying the incidence rates by the odds ratio (OR) for fracture in patients with IBD. For a hypothetical cohort of 100,000 patients, the number of years of life lived at each year of age was estimated using all-cause mortality rates for the general
Table 1. Characteristics of Fracture Cases and Controls

\begin{tabular}{lcr}
\hline \multicolumn{1}{c}{ Characteristics } & $\begin{array}{c}\text { Fracture cases }(\%) \\
(\mathrm{n}=231,778)\end{array}$ & $\begin{array}{c}\text { Controls }(\%) \\
(\mathrm{n}=231,778)\end{array}$ \\
\hline Age $(y r)$ & $55,519(24.0)$ & $56,117(24.2)$ \\
$\leq 30$ & $46,867(20.2)$ & $46,728(20.2)$ \\
$31-45$ & $40,843(17.6)$ & $40,914(17.7)$ \\
$46-60$ & $88,549(38.2)$ & $88,019(38.0)$ \\
$\quad \geq 61$ & $121,615(52.5)$ & $121,615(52.5)$ \\
Sex & $110,163(47.5)$ & $110,163(47.5)$ \\
$\quad$ Female & & \\
$\quad \begin{array}{l}\text { Male } \\
\text { Drug use in 6 months before }\end{array}$ & & \\
$\quad$ index date & $32,209(13.9)$ & $21,013(9.1)$ \\
$\quad \begin{array}{l}\text { Nonsteroidal anti- } \\
\text { inflammatory drugs }\end{array}$ & $22,328(9.6)$ & $14,466(6.2)$ \\
$\quad$ Hypnotics/anxiolytics & & \\
Medical history & & \\
$\quad \begin{array}{l}\text { Chronic obstructive } \\
\text { pulmonary disease }\end{array}$ & $41,912(18.1)$ & $28,542(12.3)$ \\
$\quad$ Cerebrovascular disease & $10,846(4.7)$ & $7545(3.3)$ \\
\hline
\end{tabular}

population of England and Wales. The estimated years of life were multiplied by the corresponding fracture incidence rates to give the expected number of fractures in the hypothetical cohort for each year of age and the 10-year risk of fracture. ${ }^{32}$

\section{Statistical Methods}

Conditional logistic regression was used to estimate ORs for the risk of fracture in patients with IBD. The analysis was controlled for a wide range of clinical variables and medication use that are possibly associated with risk of fracture, including history of heart failure, cerebrovascular disease, diabetes mellitus, rheumatoid arthritis, psychotic disorder, depression, thyrotoxicosis, seizure, and chronic obstructive pulmonary disease. Prescriptions in the 6 months before the index date for thiazides, hormone replacement therapy, nonsteroidal anti-inflammatory drugs, hypnotics/anxiolytics, antipsychotics, antidepressants, antiepileptics, anti-Parkinson drugs, and inhaled corticosteroids and bronchodilators were also considered potential confounding variables. Smoking history and body mass index were also included if entered in the database. Because smoking history and body mass index were not part of the standard data collection, this information was missing for about one half of the patients.

\section{Results}

There were 231,778 case patients with a history of fracture in the study population. A total of $52.5 \%$ were female, and 38\% were older than 60 years. As expected, control patients had a similar sex and age distribution (Table 1). Case patients had an increased prevalence of chronic obstructive pulmonary disease and prior use of hypnotics and anxiolytics than control patients. In subjects in whom it was recorded, body mass index was related to the risk of hip fracture (adjusted OR of 1.72 [95\% confidence interval (CI), 1.52-1.95] for 


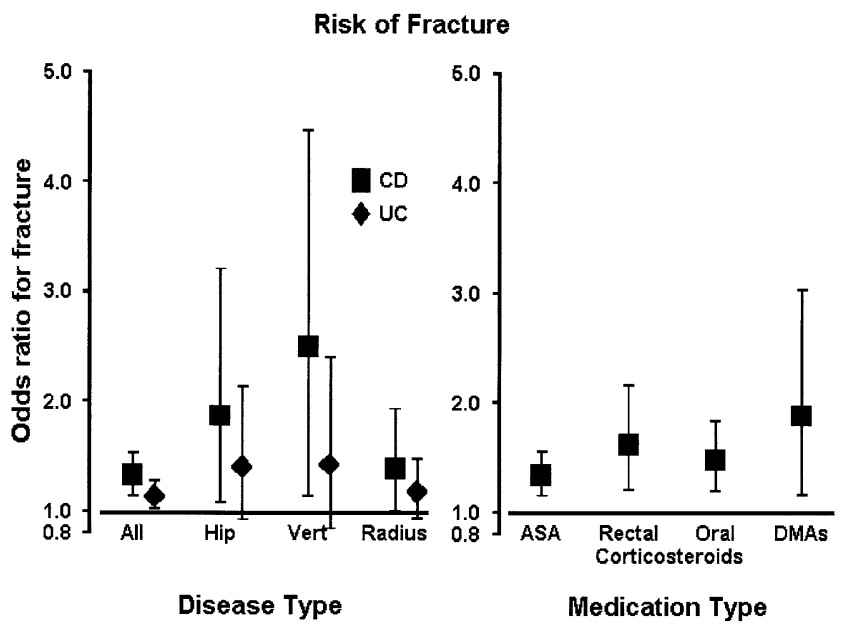

Figure 1. OR $(95 \% \mathrm{Cl})$ for fracture adjusted for comorbid diseases and medications in patients with $\mathrm{CD}$ and $\mathrm{UC}$ by disease type. Clinically symptomatic vertebral fractures are presented, and fractures of the distal forearm are included in the radial fracture group.

patients with a body mass index $<20 \mathrm{~kg} / \mathrm{m}^{2}$ and OR of 0.48 [95\% CI, 0.42-0.55] for patients with a body mass index $>30 \mathrm{~kg} / \mathrm{m}^{2}$ ).

A diagnosis of IBD was recorded for 2102 patients (725 patients with CD and 1305 patients with UC), giving a point prevalence of 156 per 100,000 for $\mathrm{CD}$ and 282 per 100,000 for UC. A total of 1134 of the case patients had a diagnosis of IBD compared with 896 of the control patients (adjusted OR, 1.21; 95\% CI, 1.101.32). The increased OR for fracture was most marked at the hip and spine. Patients with CD had a higher risk of fracture than patients with UC at all sites (Figure 1). Compared with control patients, the risk of hip fracture was increased by $86 \%$ in patients with CD and by $40 \%$ in patients with UC. The increased risk of fracture attributable to IBD did not differ between men and women (men: OR, 1.19; 95\% CI, 1.03-1.38; women: OR, 1.22; 95\% CI, 1.08-1.36).

A history of symptoms such as diarrhea, abdominal pain, anemia, rectal bleeding, weight loss, or hospitalization for a gastrointestinal disorder was associated with a higher risk of fracture than patients with IBD without such a history (OR, 1.42-1.70) (Figure 2). Disease severity, as assessed by the number of recorded symptoms, was related to the risk of fracture (no symptoms: OR, 1.02 [95\% CI, 0.90-1.17]; 1 symptom: OR, 1.66 [95\% CI, 1.41-1.96]; $\geq 2$ symptoms: OR, $1.74[95 \% \mathrm{CI}$, 1.43-2.12]) (Table 2). For hip fractures, the increased risk was greater (no symptoms: OR, 1.26 [95\% CI, 0.74-2.14]; 1 symptom: OR, 1.77 [95\% CI, 1.023.10]; $\geq 2$ symptoms: OR, 3.56 [95\% CI, 1.71-7.41]). After taking into account this measure of disease severity, there were no statistically significant differences in risk of fracture between patients with $\mathrm{CD}$ and patients with UC ( $\geq 2$ symptoms and CD: OR, $1.76[95 \% \mathrm{CI}$, 1.27-2.44); $\geq 2$ symptoms and UC: OR, 1.70 [95\% CI, $1.31-2.19])$.

Drug therapy for IBD was associated with an increased risk of fracture (OR, 1.32-1.86). The risk of fracture was greatest in patients receiving disease-modifying drugs (Figure 1). However, as expected, the use of therapy was associated with measures of disease severity such that use of oral corticosteroids was $19.6 \%$ in patients with no symptoms, $38.2 \%$ in those with 1 symptom, and $53.2 \%$ in those with $\geq 2$ symptoms. The increased risk of fracture associated with corticosteroid use persisted after adjustment for disease severity (adjusted OR for fracture in all patients with IBD was 1.10 [95\% CI, 1.00-1.20]); for hip fracture, the OR was 1.46 (95\% CI, 1.04-2.04). The risk of fracture remained related to the number of symptoms after additional adjustment for use of oral corticosteroids (no symptoms, 0.98 [95\% CI, 0.861.12]; 1 symptom, 1.50 [95\% CI, 1.28-1.77]; $\geq 2$ symptoms, 1.53 [95\% CI, 1.26-1.87]). For hip fractures, the ORs were 1.20 (95\% CI, 0.70-2.04), 1.69 (95\% CI, 0.97-2.96), and 2.96 (95\% CI, 1.42-6.16), respectively.

We were unable to show a significantly increased risk of fracture in patients who had undergone bowel surgery (OR, 1.03; 95\% CI, 0.84-1.28). Colonic surgery accounted for $73.1 \%$ of all gastrointestinal surgery; however, colonic surgery was not associated with an increased risk of fracture in patients with either CD or UC.

Table 3 summarizes the estimated 10-year risks of fracture among men and women with IBD. The risk of

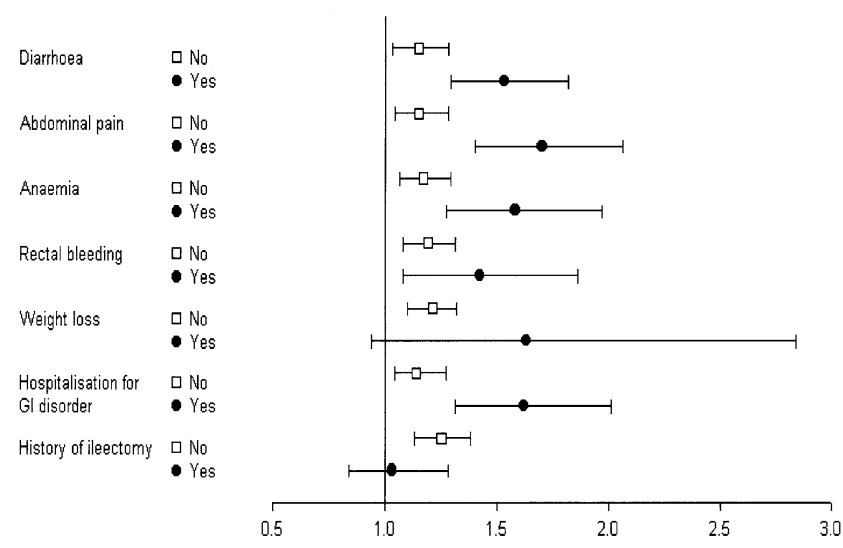

Figure 2. OR $(95 \% \mathrm{Cl})$ for fracture at all sites in patients with a history of IBD by type of symptom and history of hospitalization in the year before the index date of fracture. Risk of fracture is adjusted for comorbid disease and medications. The reference group consisted of age- and sex-matched subjects without a history of IBD and without a history of the above symptoms or hospitalization for a gastrointestinal disorder. 
Table 2. Risk of Fracture in Patients With IBD for Different Types of Fracture According to Disease Severity

\begin{tabular}{|c|c|c|c|c|c|}
\hline $\begin{array}{l}\text { Fracture } \\
\text { type }\end{array}$ & $\begin{array}{c}\text { No. of } \\
\text { symptoms }\end{array}$ & $\begin{array}{l}\text { No. of } \\
\text { cases }\end{array}$ & $\begin{array}{r}\text { No. of } \\
\text { controls }\end{array}$ & Crude OR $(95 \% \mathrm{Cl})$ & $\begin{array}{c}\text { Adjusted OR } \\
\quad(95 \% \mathrm{Cl})\end{array}$ \\
\hline \multirow[t]{3}{*}{ Any } & 0 & 451 & 474 & $1.07(0.94-1.22)$ & $1.02(0.90-1.17)$ \\
\hline & 1 & 396 & 249 & $1.79(1.53-2.10)$ & $1.66(1.41-1.96)$ \\
\hline & $\geq 2$ & 287 & 173 & 1.95 (1.61-2.36) & $1.74(1.43-2.12)$ \\
\hline \multirow[t]{3}{*}{ Hip } & 0 & 36 & 32 & $1.36(0.84-2.20)$ & $1.26(0.74-2.14)$ \\
\hline & 1 & 37 & 23 & $1.95(1.15-3.31)$ & $1.77(1.02-3.10)$ \\
\hline & $\geq 2$ & 33 & 11 & $3.63(1.82-7.23)$ & $3.56(1.71-7.41)$ \\
\hline \multirow[t]{3}{*}{ Vertebral } & 0 & 21 & 20 & $1.25(0.67-2.32)$ & $1.38(0.71-2.69)$ \\
\hline & 1 & 34 & 7 & $6.37(2.79-14.56)$ & $5.24(2.21-12.41)$ \\
\hline & $\geq 2$ & 19 & 13 & $1.84(0.89-3.78)$ & $1.33(0.60-2.96)$ \\
\hline \multirow[t]{3}{*}{ Radius/ulna } & 0 & 114 & 109 & $1.15(0.88-1.50)$ & $1.12(0.86-1.47)$ \\
\hline & 1 & 79 & 49 & $1.84(1.28-2.63)$ & $1.69(1.17-2.44)$ \\
\hline & $\geq 2$ & 60 & 34 & $1.95(1.28-2.98)$ & $1.61(1.05-2.48)$ \\
\hline
\end{tabular}

aPrior history of diarrhea, abnormal pain, anemia, rectal bleeding, or weight loss.

${ }^{b}$ Adjusted for medications and illnesses associated with risk of fracture (as outlined in Patients and Methods) and smoking history and body mass index when known.

fracture increased by age and by the number of IBD symptoms. At 65 years of age, the 10-year risk of hip fracture was $7.0 \%$ in women with IBD and $\geq 2$ symptoms. Among men, this figure was $2.8 \%$.

Use of bone-active medication was low among the patients with IBD. In female patients with IBD aged 65 years or older with an osteoporotic fracture (hip, vertebral, or radius/ulna), only $13.1 \%$ were treated with boneactive therapy in the year following the fracture $(7.3 \%$ with bisphosphonates, $6.6 \%$ with vitamin $\mathrm{D}$, and $1.5 \%$ with hormone replacement therapy). Of the female patients with IBD aged 65 years or older who had not sustained a fracture, $5.1 \%$ were treated with bone-active therapy in the year following the index date $(0.9 \%$ with bisphosphonates, $2.8 \%$ with vitamin $\mathrm{D}$, and $1.9 \%$ with hormone replacement therapy).

\section{Discussion}

We have shown that the risk of fracture was increased in patients with IBD and related to both

Table 3. Estimated 10-Year Risk of Fracture in Patients With IBD Stratified by the Number of Symptoms

\begin{tabular}{|c|c|c|c|c|c|c|}
\hline \multirow{2}{*}{$\begin{array}{l}\text { Sex/current } \\
\text { age }(y r)\end{array}$} & \multicolumn{3}{|c|}{$\begin{array}{l}\text { No. of symptoms for } \\
\text { any fracture (\%) }\end{array}$} & \multicolumn{3}{|c|}{$\begin{array}{l}\text { No. of symptoms for } \\
\text { fracture of the } \\
\text { femur/hip (\%) }\end{array}$} \\
\hline & 0 & 1 & $\geq 2$ & 0 & 1 & $\geq 2$ \\
\hline \multicolumn{7}{|l|}{ Women } \\
\hline 50 & 10.5 & 17.5 & 19.0 & 0.5 & 0.7 & 1.2 \\
\hline 65 & 15.8 & 26.5 & 28.8 & 2.6 & 3.7 & 7.0 \\
\hline 80 & 23.2 & 38.8 & 42.3 & 11.8 & 17.0 & 31.6 \\
\hline \multicolumn{7}{|l|}{ Men } \\
\hline 50 & 7.6 & 12.8 & 13.9 & 0.3 & 0.5 & 0.9 \\
\hline 65 & 5.9 & 9.9 & 10.8 & 1.1 & 1.5 & 2.8 \\
\hline 80 & 8.6 & 14.3 & 15.6 & 4.0 & 5.7 & 10.5 \\
\hline
\end{tabular}

disease severity and use of medication. Women and men aged 65 years with severe IBD have a 10 -year probability of hip fracture of $7 \%$ and $2.8 \%$, respectively. Despite the availability of effective therapies to reduce the risk of fracture, these high-risk patients were largely untreated.

The etiology of osteoporosis and the increased risk of fracture in patients with IBD involve several factors, including vitamin D deficiency, systemic inflammation, malnutrition, and use of oral corticosteroids. It is thus of interest to establish the relative contributions of each cause, particularly the effects of the disease-related variables and oral corticosteroid therapy. However, research into this question is complex, given the close correlation between disease activity and oral corticosteroid therapy. A small cross-sectional analysis of bone mineral density (BMD) of patients with IBD reported that use of oral corticosteroids was the only statistically significant predictor of diminished BMD. The investigators concluded that decreased BMD in patients with IBD is related to use of oral corticosteroids and not to disease activity. ${ }^{3}$ In our study, adjustment for use of oral corticosteroids reduced the magnitude of but did not eliminate the increased risk of fracture in patients with IBD. This suggests that increased disease activity is itself associated with an increased risk of fracture. This may be due to malabsorption, particularly of vitamin $\mathrm{D}$, but also due to the associated increased levels of circulating cytokines that act directly on bone turnover rate. ${ }^{33}$ This is supported by our data showing that the risk of fracture increases with the number of symptoms of disease activity independently of oral corticosteroid use. However, the deleterious effects of oral corticosteroids on bone metabolism will be partially counterbalanced by their ability to reduce systemic inflammation. The challenge 
for physicians is to reduce systemic inflammation while using the lowest possible dose of oral corticosteroids.

It is well known that less than one third of all vertebral fractures identified on radiographs come to clinical attention. ${ }^{34}$ By analyzing clinically diagnosed fractures and not performing screening radiography, we will underestimate the total number of radiographic fractures in both case patients and control patients. However, this fact alone should not affect our assessment of the risk of fracture compared with controls. The data in patients with IBD confirm a high level of underreporting of radiographic vertebral fractures. ${ }^{35,36}$ Stockbrügger et al. performed radiography on 271 patients with $C D$ and found vertebral fractures in $14.2 \%$ of patients, all of whom were asymptomatic; Klaus et al. performed lumbar radiography on 156 patients with $\mathrm{CD}$ and vertebral osteopenia or osteoporosis on dual x-ray absorptiometry scanning and found vertebral fractures in $21.8 \%$, with only $2.5 \%$ reporting pain. 35,36 Both of these studies limited their assessment of recorded pain and disability to that currently experienced by the patients. They may therefore miss a significant number of patients with older fractures that may have caused pain at the time of the fracture and hence come to clinical attention but were free of pain at the time of the study. If there is greater underreporting of vertebral fractures in patients with IBD compared with controls, the relative risk of fracture may be underestimated.

Several studies have compared the risk of fracture in patients with CD and UC. Two studies conducted by Vestergaard et al. observed an increased risk of fracture in CD but not in UC. ${ }^{22,23}$ These studies were not population based (recruited from the Danish Colitis/Crohn's Association $^{22}$ and a hospital-based registry system ${ }^{23}$ ) and therefore may have represented a more select and probably severe population of patients. A cohort study of 238 patients with $\mathrm{CD}$ found no overall increase in the total risk of fracture ${ }^{37}$; however, when the osteoporotic fracture sites were analyzed separately, the investigators found relative risks similar to our study (osteoporotic, 1.4; spine, 2.2) that, due to small numbers, were not statistically significant. In agreement with our results, a previous population-based study comparing patients with IBD with the general population reported similar increases in the risk of fracture between $\mathrm{CD}$ and $\mathrm{UC}^{4}$; however, no adjustments were made for disease severity or use of corticosteroids. In this study, we found an increased risk of fracture in both diseases but greatest in patients with $\mathrm{CD}$. One explanation is that the 2 conditions differ in their effects on bone metabolism, as observed by an in vitro study of the sera of patients with
CD and UC on an organ culture of fetal rat bone. ${ }^{38}$ The second and more likely explanation for lower BMD and higher risk of fracture in $C D$ is varying disease severity. $\mathrm{CD}$ is considered a systemic disease and is often associated with a marked systemic inflammatory load, whereas UC is limited to the colonic mucosa and has a lower systemic inflammatory load. We found that patients with $\mathrm{CD}$ used oral corticosteroids more frequently and experienced more symptoms than patients with UC. Furthermore, when disease activity and use of oral corticosteroids were controlled for, we found no difference in rates of fracture between the 2 diseases.

We found that patients with IBD who have undergone bowel surgery did not have an increased risk of fracture. These findings are in agreement with those of Vestergaard et al. ${ }^{22,23}$ but contrast with the results of several BMD studies showing that BMD was reduced in patients with a history of bowel surgery. ${ }^{10,15,19}$ However, Pigot et al. reported a direct correlation between the time after surgery and BMD. ${ }^{13}$ Patients who undergo bowel surgery frequently enter clinical remission from the inflammatory disease and therefore often no longer require treatment with oral corticosteroids. The effects of oral corticosteroids on BMD are at least partially reversible after discontinuation of treatment, ${ }^{26}$ as are the effects of inflammation. This suggests that BMD may increase and the risk of fracture may decrease after successful bowel surgery.

There are now numerous treatment options available to reduce the risk of osteoporotic fracture, including calcium and vitamin $\mathrm{D}$, bisphosphonates, selective estrogen receptor modulators, and parathyroid hormone. Although these treatments have been shown to increase BMD and reduce the risk of fracture in postmenopausal osteoporosis, there are no data on fracture reduction in patients with IBD. However, the bisphosphonates alendronate and ibandronate have been proven to increase BMD in patients with $\mathrm{CD}$ to a similar degree as in patients with postmenopausal osteoporosis. ${ }^{31,39}$ In addition, despite the lack of fracture data, the American Gastroenterological Association ${ }^{40}$ recommends the use of antiosteoporosis treatments in patients at high risk of osteoporotic fracture. This study shows that most patients with IBD with a fracture and, hence, osteoporosis are not receiving bone-protective treatment. We therefore need to develop effective strategies to identify and treat these high-risk patients as a matter of priority. These treatments are not without side effects and have significant cost implications; therefore, when assessing the needs of individual patients for the strategies, it is useful to have an idea of their absolute risk of fracture 
over the next 5-10 years to target therapy more accurately. We have shown that by using a combination of age, sex, and number of symptoms, the risk of hip fracture over the ensuing 10 years can be graded from $0.3 \%$ to $31.6 \%$, with figures for any fracture ranging from $5.9 \%$ to $42.3 \%$. Although these figures are only estimates, they can provide useful additional information to other clinical and densitometric risk factors currently used.

This study has several strengths and limitations. This is the first population-based study of patients with IBD to examine the risk of fracture and to examine the main risk factors. We had relatively crude information on the disease activity of IBD, such as recorded abdominal pain, diarrhea, or rectal blood loss. Thus, it is likely that we underestimated the relationship of disease activity to the risk of fracture due to the use of nonspecific data. Because there were no data on some of the possible etiologic factors, such as malabsorption or vitamin D levels, and no data on physical activity, the evaluation of the various contributing factors was restricted. Another potential limitation concerned the ascertainment of IBD and fractures. However, we have shown point prevalences of $\mathrm{CD}$ and UC similar to other population-based studies in England. ${ }^{31}$ Furthermore, previous studies of the GPRD have reported a high level of validity with respect to ascertainment of fracture ( $>90 \%$ of fractures were confirmed). ${ }^{29,39}$

In conclusion, patients with IBD have a significantly increased risk of fracture related to the severity of their disease. This increased risk is due to a combination of disease activity and use of oral corticosteroids. As a preventive measure, we suggest that all patients with IBD receive counseling on lifestyle measures to reduce bone loss and avoid consequent fracture. Further investigations such as bone densitometry might be conveniently targeted to older patients as well as younger patients with more severe disease.

\section{References}

1. Abitbol V, Roux C, Chassade S, Guillemant S, Kolta S, Dougados M, Couturier D, Amor B. Metabolic bone assessment in patients with inflammatory bowel disease. Gastroenterology 1995;108: 417-422.

2. Ardizzone S, Bollani S, Bettica $\mathrm{P}$, Bevilacqua M, Molteni P, Porro B. Altered bone metabolism in inflammatory bowel disease: the difference between Crohn's disease and ulcerative colitis. J Intern Med 2000;247:63-70.

3. Bernstein C, Seeger L, Sayre J, Anton P, Artinian L, Shanahan F. Decreased bone density in inflammatory bowel disease is related to corticosteroid use and not disease diagnosis. J Bone Miner Res 1995;10:250-256.

4. Bernstein C, Blanchard J, Leslie W, Wajda A, Yu B. The incidence of fracture among patients with inflammatory bowel disease. Ann Intern Med 2000;133:795-799.
5. Bischoff S, Herrmann A, Goke M, Manns M, von der Muhlen A, Brabant G. Altered bone metabolism in inflammatory bowel disease. Am J Gastroenterol 1997;92:1157-1163.

6. Bjarnason I, Macpherson A, Mackintosh C, Buxton-Thomas M, Forgacs I, Moniz C. Reduced bone density in patients with inflammatory bowel disease. Gut 1997;40:228-233.

7. Clements D, Motley R, Evans W, Harries A, Rhodes J, Coles R. Longitudinal study of cortical bone loss in patients with inflammatory bowel disease. Scand J Gastroenterol 1992;27:10552060.

8. Compston J, Judd D, Crawley E, Evans WD, Evans C, Church HA, Reid EM, Rhodes J. Osteoporosis in patients with inflammatory bowel disease. Gut 1987;28:410-415.

9. Ghosh S, Cowen S, Hannan W, Ferguson A. Low bone mineral density in Crohn's disease, but not in ulcerative colitis, at diagnosis. Gastroenterology 1994;107:1031-1039.

10. Jahnsen J, Falch J, Aadland E, Mowinckel P. Bone mineral density is reduced in patients with Crohn's disease but not in patients with ulcerative colitis: a population based study. Gut 1997;40: 313-319.

11. Javaid M, McCrudden P, Taylor P, Petley GW, Stroud M, Fine DR, Cooper C, Arden NK. Comparison of calcaneal ultrasound and DXA to assess the risk of corticosteroid-induced osteoporosis: a cross-sectional study. Osteoporos Int 2001;12:788-793.

12. Motley R, Clements D, Evans W, Crawley EO, Evans C, Rhodes J, Compston JE. A four-year longitudinal study of bone loss in patients with inflammatory bowel disease. Bone Miner 1993;23: 95-104.

13. Pigot F, Roux C, Chaussade S, Hardelin D, Pelleter O, Du Puy Montbrun T, Listrat V, Dougados M, Couturier D, Amor B. Low bone mineral density in patients with inflammatory bowel disease. Dig Dis Sci 1992;37:1396-1403.

14. Pollak R, Karmeli F, Eliakim R, Ackerman Z, Tabb K, Rachmilewitz D. Femoral neck ostepenia in patients with inflammatory bowel disease. Am J Gastroenterol 1998;93:1483-1490.

15. Robinson RJ, al-Azzawi F, lqbal SJ, Kryswcki T, Almond L, Abrams $\mathrm{K}$, Mayberry JF. Osteoporosis and determinants of bone density in patients with Crohn's disease. Dig Dis Sci 1998;43:25002506.

16. Schoon E, Blok B, Geerling J, Russel M, Stockbrügger R, Brummer R. Bone mineral density in patients with recently diagnosed inflammatory bowel disease. Gastroenterology 2000;119:12031208.

17. Schoon E, van Nunen A, Wouters R, Stockbrügger R, Russel M. Osteopenia and osteoporosis in Crohn's disease: prevalence in a Dutch population-based cohort. Scand J Gastroenterol 2000;4347.

18. Schulte C, Dignass A, Mann K, Goebell H. Reduced bone mineral density and unbalanced bone metabolism in patients with inflammatory bowel disease. Inflamm Bowel Dis 1998;4:268-275.

19. Silvennoinen J, Karttunen T, Niemelä S, Manelius J, Lehtola J. A controlled study of bone mineral density in patients with inflammatory bowel disease. Gut 1995;37:71-76.

20. Tromm A, Rickels K, Huppe D, Wiebe V, May B. Osteopenia in chronic inflammatory bowel diseases. (in German) Leber Magen Darm 1994;24:2330.

21. Ulivieri FM, Piodi LP, Taioli E, Lisciandrano D, Ranzi T, Vezzoli M, Cermesoni L, Bianchi P. Bone mineral density and body composition in ulcerative colitis: a six-year follow-up study. Osteoporos Int 2001;12:343-348.

22. Vestergaard $\mathrm{P}$, Krogh $\mathrm{K}$, Rejnmark L, Laurberg S, Mosekilde L. Fracture risk is increased in Crohn's disease, but not in ulcerative colitis. Gut 2000;46:176-181.

23. Vestergaard $P$, Mosekilde L. Fracture risk in patients with celiac disease, Crohn's disease, and ulcerative colitis: a nationwide follow-up study of 16,416 patients in Denmark. Am J Epidemiol 2002;156:1-10. 
24. Von Tirpitz C, Pischulti G, Klaus J, Rieber A, Bruckel J, Bohm BO, Adler G, Reinshagen M. Pathological bone density in chronic inflammatory bowel diseases-prevalence and risk factors. (in German) Z Gastroenterol 1999;37:512.

25. Schoon E, Wolffenbuttel B, Stockbrügger R. Osteoporosis as a risk in inflammatory bowel disease. Drugs Today 1999;35:1728.

26. Van Staa T, Leufkens H, Abenhaim L, Zhang B, Cooper C. Use of oral corticosteroids and risk of fractures. J Bone Miner Res 2000;15:1001-1005.

27. Van Staa T, Leufkens H, Cooper C. The epidemiology of corticosteroid-induced osteoporosis-a meta-analysis. Osteoporos Int 2002;13:777-787.

28. Walley T, Mantgani A. The UK General Practice Research Database. Lancet 1997;350:1097-1099.

29. Van Staa T, Abenhaim L. The quality of information recorded on a UK database of primary care records: a study of hospitalisation due to hypoglycemia and other conditions. Pharmacoepidemiol Drug Saf 1994;3:15-21.

30. Lewis J, Brensinger C, Bilker W, Strom B. Validity and completeness of the general practice research database for studies of inflammatory bowel disease. Pharmacoepidemiol Drug Saf 2002; 11:211-218.

31. Rubin G, Hungin A, Kelly PJ, Ling J. Inflammatory bowel disease: epidemiology and management in an English general practice population. Aliment Pharmacol Ther 2000;14:1553-1559.

32. Van Staa T, Dennison E, Leufkens H, Cooper C. The epidemiology of fractures in England and Wales. Bone 2001;29:517-522.

33. Sylvester F, Wyzga N, Hyams J, Gronowicz G. Effect of Crohn's disease on bone metabolism in vitro: a role for interleukin-6. J Bone Miner Res 2002;17:695-702.

34. Cooper C, O'Neill T, Silman A. The epidemiology of vertebral fractures. European Vertebral Osteoporosis Study Group. Bone 1993;14:589-597.

35. Klaus J, Armbrecht G, Steinkamp M, Bruckel J, Rieber A, Adler G, Reinshagen M, Felsenberg D, von Tirpitz C. High prevalence of osteoporotic vertebral fractures in patients with Crohn's disease. Gut 2002;51:654-658.
36. Stockbrügger RW, Schoon EJ, Bollani S, Mills PR, Israeli E, Landgraf L, Felsenberg D, Ljunghall S, Nygard G, Persson T, Graffner $\mathrm{H}$, Bianchi Porro G, Ferguson A. Discordance between the degree of osteopenia and the prevalence of spontaneous vertebral fractures in Crohn's disease. Aliment Pharmacol Ther 2002;16: 1519-1527.

37. Loftus E, Crowson C, Sandborn W, Tremaine W, O'Fallon W, Melton LJ. Long-term fracture risk in patients with Crohn's disease: a population-based study in Olmstead County, Minnesota. Gastroenterology 2002;123:468-475.

38. Hyams J, Wyzga N, Kreutzer D, Justinich C, Gronowicz G. Alterations in bone metabolism in children with inflammatory bowe disease: an in vitro study. J Pediatr Gastroenterol Nutr 1997;24: 289-295.

39. Van Staa T, Abenhaim L, Cooper C, Begaud B, Zhang B, Leufkens $\mathrm{H}$. The use of a large pharmaco-epidemiological database to study exposure to oral corticosteroids and risk of fractures: validation of study population and results. Pharmacoepidemiol Drug Saf 2000;9:359-366.

40. American Gastroenterological Association. American Gastroenterological Association medical position statement: guidelines on osteoporosis in gastrointestinal diseases. Gastroenterology 2003;124:791-794.

Received June 12, 2003. Accepted September 4, 2003.

Address requests for reprints to: Nigel K. Arden, M.R.C.P., M.Sc., M.D., Medical Research Council Environmental Epidemiology Unit, Southampton General Hospital, University of Southampton, Southampton S016 6YD, England. e-mail: nka@mrc.soton.ac.uk; fax: (44) 02380704021.

Supported by the Procter \& Gamble Pharmaceuticals, Arthritis Research Campaign (to N.K.A.).

The authors thank EPIC for their support in providing the General Practice Research Database data.

T.-P.V. works for Procter \& Gamble Pharmaceuticals, which has an interest in osteoporosis. 